\title{
Síndrome do jejuno hemorrágico em bovinos no estado de Pernambuco - relato de dois casos
}

Ângela Imperiano da Conceição; Nivan Antonio Alves da Silva, Rodolfo José Cavalcanti Souto, Maria Isabel de Souza, Nivaldo de Azevedo Costa, Jobson Filipe de Paula Cajueiro, José Augusto Bastos Afonso, Carla Lopes de Mendonça, Luiz Teles Coutinho

Clínica de Bovinos, Universidade Federal Rural de Pernambuco (UFRPE), Garanhuns, PE, Brasil

*Autor correspondente

e-mail: angelaimperiano@hotmail.com

\section{Resumo}

A síndrome do jejuno hemorrágico ( $\mathrm{SJH}$ ) caracteriza-se, em bovinos adultos, por enterite necro-hemorrágica aguda, com formação de coágulos sanguíneos, podendo levar à obstrução intestinal. Sua ocorrência tem sido relatada em rebanhos leiteiros de vários países, no entanto, no Brasil o seu diagnóstico ainda é pouco reportado. O objetivo deste trabalho é relatar a ocorrência da SJH no estado de Pernambuco, onde duas vacas oriundas de propriedades distintas, com histórico de inapetência, redução na produção leiteira, sinais de dor e fezes sanguinolentas e em jatos, foram atendidas na Clínica de Bovinos, campus Garanhuns, Universidade Federal Rural de Pernambuco (CBG/UFRPE). O exame clínico revelou (no animal 01 e/ou no animal 02) apatia, desidratação, taquicardia, anorexia, hipomotilidade digestiva, ressonância metálica à direita e cólica. As fezes do animal 1 eram escassas e com característica de melena, enquanto que no animal 2 eram em jatos e de aspecto sanguinolento. A análise do fluído ruminal revelou comprometimento da fauna e flora e elevação nos teores de cloretos das amostras. O hemograma demonstrou inversão da proporção linfócito/ segmentados e hiperfibrinogenemia no primeiro animal, enquanto que no segundo ocorreu leucocitose por neutrofilia com desvio regenerativo para esquerda e hipoproteinemia. A ultrassonografia evidenciou hipomotilidade reticular e intestinal, além de dilatação dos intestinos e presença de conteúdo ecogênico em sua luz, sugestivo de coágulos sanguíneos. Em função da suspeita clínica inicial de obstrução intestinal no animal 1, este foi submetido à laparotomia exploratória à direita, na qual se constatou uma porção do jejuno aproximadamente $40 \mathrm{~cm}$ de extensão - aumentada de volume, edemaciada, congesta, com áreas de necrose e deposição de fibrina sobre a serosa. Esse segmento comprometido foi removido, mediante entero-anastomose término-terminal, e sua análise após ressecção cirúrgica revelou tratar-se de obstrução intestinal por coágulos sanguíneos, caracterizando, assim, o diagnóstico de SJH. O pós-cirúrgico foi composto por medicação antiinflamatória não esteroide, antibiótico, pró-cinético, e terapia adjuvante - cálcio, reposição hidroeletrolítica, 
transfaunação e suco de mandacaru (laxativo natural obtido do cacto mandacaru). 0 diagnóstico no animal 2 baseou-se na interpretação conjunta das informações epidemiológicas e clínico-laboratoriais, além das imagens ultrassonográficas, que são, segundo a literatura, características de SJH. Apesar do teor de cloreto elevado, esse animal não apresentava outras características de obstrução intestinal, optando tratálo conservativamente com anti-inflamatório não esteroide, antibióticos, protetor de mucosa associado à terapia adjuvante supracitada. A abordagem, diagnóstica e terapêutica empregada nos animais deste estudo foi eficiente, uma vez que promoveu satisfatória recuperação clínica dos animais, ratificando desta forma a ocorrência da síndrome. Acredita-se que, pelo caráter agudo e grave da enfermidade, a rápida procura por auxílio veterinário possa ser fator decisivo no prognóstico dos animais acometidos. 